claim is excessive secrecy surrounding the commission's scientific committees, and question their legitimacy.

EU measures on BSE must be approved by either the standing veterinary committee - made up of the chief veterinary officers of member states - or the agriculture council. The commission submits proposals to them after taking advice from its scientific veterinary committee (SVC), made up scientists selected by the commission from nominations by the member states. The SVC itself has a working party on BSE, made up of outside experts.

The fact that members of the SVC are appointed by member states undermines its independence, argue critics. "While the commission says it relies on science, one wonders how objective this science is within these committees," says Collins. "People on these are almost all appointees of national governments and in some sense represent their government's points of view."

Such concerns are heightened by the secrecy in which the committees operate. "The problem is to know what the hell is going on in these committees," says one official at the parliament. Allegations of excessive secrecy are confirmed by Hoelgaard, who himself says: "Speaking as Dane, I have been quite shocked and amazed by procedures in the commission."

The competence of some members of the SVC is also questioned by some scientists. One recalls a meeting of the SVC in July on the risk of BSE in sheep. The SVC's working party on BSE had prepared "an interesting and rich working document", according to the observer, but it passed over the heads of most of those present.

The document was made available to the SVC only at the meeting, and committee members lacked time to consider it. The discussion, claims the observer, was "psychedelic" with "almost

half" the members failing to grasp that it concerned the risk of BSE in sheep, and not scrapie.

The creation last summer of a multidisciplinary committee on BSE to advise the commission is an admission of the flaws in the scientific veterinary

committee, according to observers. "The commission realized that it had to diminish the excessive power of DG6 [the agriculture directorate]," says one scientist involved.

Evidence of interference by DG6 comes from a stormy meeting of the industry directorate's scientific food committee on 8 March, almost two weeks before the UK government announced a possible link between BSE and CJD. One member of the committee says that Brian Marchant, a civil servant in DG6, disputed the meeting's decision not to take a position on the unilateral exclusion by France and Germany of certain bovine materials from baby food, because it considered that the risk of BSE could not be excluded. Marchant "treated us as if we were incompetent and thought we were wrong to take a position that was different from the scientific veterinary committee", he says.

One outcome of the BSE crisis, admits one commission official, is that it has vindicated the Parliament's long-standing criticism of the system of committees. The BSE crisis has exposed that this system means that it "is hard to see who is responsible" for decisions.

A wide-ranging reorganization of the commission services is likely to result from a confidential audit of DG6's veterinary services commissioned by Legras from the commission's general inspectorate, which reports direct to Jacques Santer, the commission president.

One official from the parliament's environment committee says it is keen to have animal health and its consequences for public health moved out of DG6. It wants this activity to be combined with health currently part of the directorate for employment and social affairs (DG5) - and shifted to the directorate for consumer protection (DG24). Only in this way can "the inherent conflict of interest" of handling health matters within the powerful agriculture directorate be avoided, he says. Declan Butler

\title{
Australian reef fisheries project swims for survival
}

Sydney. A decision by the Australian government to approve a project designed to evaluate the effects of line fishing and the rates of recovery of commercial and recreational species on the Great Barrier Reef (GBR) is being challenged in the federal parliament.

If the project proceeds, it will be the first controlled test of 'adaptive management' of coral reefs and the first in a marine World Heritage Area. Opposition to it focuses on the procedures for assessing the environmental impact of the survey, and on an alternative proposal for closing reefs as a precautionary measure.

Led by Bruce Mapstone, a biologist at the Cooperative Research Centre for Reef Research (CRC) in Townsville, Queensland, the programme is planned to last between five and ten years, and will be run in collaboration with the commercial and recreational fishing industries on 24 reefs selected from 3,000 within the $2,000-\mathrm{km}$ long GBR Marine Park.

In each of four clusters of six reefs, fishing will be allowed in two 'green reefs', currently closed to fishing. Two 'blue reefs' now open to fishing will be subjected to greater pressure for 12 months before being closed, and two reefs will be controls. After a year of measured harvesting, coral trout (the basis of the industry) are expected to decline by 50 to 60 per cent, and the fished reefs will be closed for five years to measure their rates of recovery.

Fisheries around the world experiencing sudden collapses have done so without warning. The GBR experiment follows studies by Campbell Davies of the CRC, showing that coral trout do not migrate between different reefs. It is designed to measure how vulnerable or robust a fishery is under the pressure of fishing, and the effectiveness of reef closures as a means of replenishing stocks.

The experiment is supported by the Australian Marine Sciences Association, and has been approved by Robert Hill, the Minister for the Environment. But there has been vehement opposition from local conservation groups, as well as the Australian Democrats Party in the Senate. They claim that Hill by-passed a legal requirement to take note of advice from statutory authorities - which he denies.

Meg Lees, the Democrats' environment spokeswoman, is seeking to reverse Hill's change of zoning regulations for the GBR, attacking him for bowing to pressure from the commercial industry and asserting that his policies "would rip the heart out of some of the few protected regions of the GBR".

\section{IMAGE UNAVAILABLE FOR COPYRIGHT REASONS}

All at sea? Critics point to conservation risks.

There have been only three other experiments in adaptive management, two in Canada and one in the Philippines. Carl Walters of the University of British Columbia, Canada, says that there is no direct experimental evidence to support adaptive management of reef fisheries. Most of the reefs in the GBR are now at risk of impacts from recreational and commercial fishing, he says. "We do not understand those impacts, and cannot model them correctly with available information." Peter Pockley 